\title{
La humanización del proceso en el trámite en la Jurisdicción Especial de Paz: un factor de legitimidad de la justicia ${ }^{1}$
}

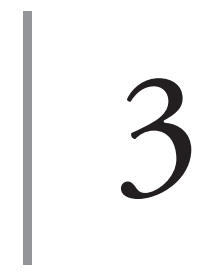

https://doi.org/10.21830/9789585284883.03

\author{
Manuel Bermúdez-Tapia ${ }^{2}$ \\ Universidad Privada San Juan Bautista \\ Paola Alexandra Sierra-Zamora ${ }^{3}$ \\ Escuela Militar de Cadetes "General José María Córdova” \\ Julián Alberto Cardona Espinosa ${ }^{4}$ \\ Escuela de Aviación del Ejército
}

1 Este capítulo hace parte del trabajo colaborativo de dos proyectos de investigación: 1) "Perspectivas en Derechos Humanos y Derecho Internacional Humanitario para el Ejército Nacional de Colombia” del Grupo de Investigación en Aviación Militar de la Escuela de Aviación del Ejército, registrado con el código COL0077618 y categorizado en C por Minciencias, y 2) "Relaciones civiles-militares en Colombia: una aproximación a los roles de las Fuerzas Militares” del Grupo de Investigación en Ciencias Militares de la Escuela Militar de Cadetes "General José María Córdova”, registrado con el código COL0082556 y categorizado en B por Minciencias. Los puntos de vista pertenecen a los autores y no reflejan necesariamente los de las instituciones participantes.

2 Abogado (magna cum laude) de la Pontificia Universidad Católica del Perú. Magíster en Derecho y PhD en Derecho por la Pontificia Universidad Católica de Argentina. Profesor-investigador de la Universidad Privada San Juan Bautista y profesor de la Facultad de Derecho de la Universidad Nacional Mayor de San Marcos. Orcid: http://orcid.org/0000-0003-1576-9464 - Contacto: manuel.bermudez@upsjb. edu.pe

3 Abogada de la Universidad Católica de Colombia. Magíster en Derechos Humanos, Democracia y Justicia Internacional por la Universitat de València, España. PhD (c) del Programa de Derechos Humanos, Democracia y Justicia Internacional por la Universitat de Valéncia, España. Investigadora del "Grupo de Investigación en Ciencias Militares" de la Escuela Militar de Cadetes "General José María Córdova”. Orcid: https://orcid.org/0000-0002-3146-7418. Contacto: paola.sierra@esmic.edu.co

4 Coronel del Ejército Nacional de Colombia. Especialista en Seguridad y Defensa Nacionales, Escuela Superior de Guerra "General Rafael Reyes Prieto", Colombia. Especialista en Administración de Recursos Militares para la Defensa Nacional y en Ciencias Militares para el Planeamiento, Centro de Educación Militar, Colombia. Especialista en Gerencia de Talento Humano, Universidad Sergio Arboleda, Colombia. Profesional en Ciencias Militares, Escuela Militar de Cadetes "General José María Córdova”, Colombia. Orcid: https://orcid.org/0000-0002-1187-1739 - Contacto: julian.cardona@buzonejercito.mil.co 


\section{Introducción}

Producto de la inserción de conceptos constitucionales de defensa de los derechos humanos y de los derechos fundamentales, el proceso judicial (en general) se ha visto inmerso en constantes reformas y readaptaciones de sus propios contenidos con el fin de optimizar sus alcances, principalmente, al ser tomado como un mecanismo para impartir justicia (Uprimny, 2006).

De esta manera, los valores constitucionales de tutela de derechos fundamentales se han vinculado al ámbito procesal y se ha mejorado la concepción y aplicación de principios como el debido proceso, la tutela jurisdiccional efectiva, la imparcialidad judicial y la procura de la economía procesal, entre otros (Casal, 2008).

Sin embargo, entre estos principios existe todavía una consideración más práctica que teórica, que no permite señalar una equivalencia entre ellos, debido sobre todo a la manera como se desarrolla la implementación e inicio de actividades en Colombia de la Jurisdicción Especial para la Paz (SierraZamora \& Jiménez Barrera, 2019).

En este contexto, desarrollaremos un aspecto poco valorado en el ámbito del servicio de impartición de justicia que desarrollan las entidades vinculadas al ámbito jurisdiccional. Dicho ámbito hace referencia a la manera en que estas entidades valoran la condición del justiciable respecto del factor temporal del desarrollo del proceso.

El tiempo es por tanto un factor sumamente importante que puede provocar la ampliación de situaciones de desventaja, perjuicio o lesión de derechos complementarios que usualmente no logra ser analizado diligentemente, dado que se ponderan otros principios de naturaleza procesal y constitucional mucho más relevantes a criterio de la doctrina, pero que esencialmente no logran atender las necesidades de quienes están involucrados en una situación negativa a consecuencia de terceras personas.

\section{El tiempo excesivo del proceso como perjuicio al concepto de "sujeto de derecho"}

El trámite de un proceso judicial, sin importar su naturaleza, permite observar una condición sumamente específica: se desarrolla en un plazo 
relativamente extenso, frente al parámetro temporal que es determinado por la normatividad procesal (Gozaíni, 2016). Esta situación, es conocida por la comunidad en forma general y hace parte de un valor referencial que incide en la evaluación de sus derechos (Lanzarote Martínez, 2005). De este modo, se genera una situación muy particular en el ciudadano que participa en un proceso en cualquiera de sus dos niveles (demandante o demandado; imputado o víctima en un proceso penal), al estar inmerso, y prácticamente atado de manos, ante las entidades que conforman el Sistema de Impartición de Justicia, porque la indeterminación de un derecho, obligación o condición, se encuentra pendiente de una decisión definitiva en un periodo de tiempo cuya proyección es imponderable.

Sobre estas líneas es posible identificar el impacto negativo que recae sobre el ámbito de la práctica de la Jurisdicción Especial de Paz (en adelante, JEP), en particular, cuando se tiene que analizar el contexto sociofamiliar de las víctimas, cuyos "sucesores" deben participar de un proceso judicial, en vez de que lo haga el familiar afectado en sus derechos, lo que amplía el factor negativo en la impartición de justicia (Bermúdez-Tapia, 2014a)

Nótese que la sucesión procesal no puede atender el problema humano que asume la persona que continúa el trámite judicial y que, eventualmente, así sea indemnizado o compensado, esta acción no podrá atender el factor psicológico y personal de quien ya no cuenta con el familiar que ha sido víctima o se le ha lisiado su derecho.

Se añade negativamente a esta situación, la amplitud de la ejecución de una sentencia, que implica un mayor tiempo del propio proceso, con lo cual resulta objetiva la condición perjudicial en el justiciable: a pesar de ser victorioso en la instancia judicial, resulta víctima de las condiciones internas y externas del sistema de impartición de justicia, que incluye a la JEP (Rodés Mateu, 2009).

En este punto, consideramos que el valor y legitimidad que tendrá la JEP no podrá atender debidamente las iniciales pretensiones de los sucesores de muchas víctimas del conflicto armado interno (Sain, 2018), pero eventualmente podrá asumir un rol proactivo en la tutela de aquellos derechos que merecen ser develados, porque en la actualidad han quedado en la sombra.

Además, frente a estas condiciones, en el ámbito de la justicia ordinaria, también puede ocurrir otra situación particular, que es la ejecución de recursos ante diferentes órganos jurisdiccionales, con lo cual se podría 
provocar la intervención de otros órganos jurisdiccionales, sin que ello implique una situación final, porque de por medio se debe entender que las resoluciones que dichas instancias deberán ser actuadas por los órganos jurisdiccionales de primera instancia. La opción de ampliar este contexto procesal a la intervención de la Comisión Interamericana de Derechos Humanos y la Corte Interamericana de Derechos Humanos en forma conjunta evidenciaría que estamos ante una situación de temporalidad sumamente prolongada (Padrón \& Correa, 2018, p. 43), factor que desnaturaliza el sentido de tutela judicial efectiva (Pérez del Blanco, 2003, p. 171).

El tiempo en evaluación permite considerar que el ciudadano deja de ser una figura de tutela (sujeto de derechos), porque la ambigüedad de su condición frente a un tercero, sea cual fuere esta, no provoca un nivel de seguridad en sus acciones tanto personales como sociales, y ello restringe en esencia sus propias condiciones personales (Rosales, 2008, p. 75).

Consideramos, en este contexto, la necesidad de reevaluar dos condiciones autónomas pero complementarias entre sí, que se vinculan con el ámbito temporal en el que se desarrolla un proceso judicial: el plazo razonable en el cual se debe desarrollar un procedimiento judicial y el principio de la economía procesal, que señala una metodología en función de las condiciones de los derechos en cuestión y el procedimiento jurisdiccional aplicable.

\section{La determinación y evaluación de un plazo razonable}

Observamos que el proceso judicial, en cualquier especialidad y ámbito competencial, está vinculado a una esfera constitucional de tutela de los derechos básicos y referenciales de toda persona en el ámbito jurisdiccional y que, por ello, se estructuran y relacionan —a partir del derecho al debido proceso y la tutela jurisdiccional efectiva — una serie de derechos que actúan como un conjunto de principios y disposiciones de carácter normativo y procedimental. Sin embargo, esta situación nos permite analizar la legitimidad funcional de la JEP en el ámbito de la impartición de justicia, con base en la evaluación de la garantía del debido proceso y de la tutela jurisdiccional efec- 
tiva aplicables al propio proceso en curso, porque esencialmente los hechos que deberá atender se han ejecutado en un periodo de tiempo sumamente amplio y distante de la actualidad (Eser et al., 2018, p. 13).

A partir de dicha evaluación, observamos un resultado negativo, principalmente, por las condiciones que afectan el desarrollo oportuno en términos temporales de los procesos judiciales en la JEP, debido a la carga procesal que tiene y que se incrementará en los próximos años. Sea cual fuere la consecuencia, el resultado provoca una situación de crisis del propio sistema en general, por cuanto el plazo que debe corresponder a la tramitación ordinaria de un proceso se excede en cuanto a los tiempos establecidos, puesto que la normatividad procesal se extiende en el tiempo y no se da una evaluación de este aspecto en el proceso (Salazar Murillo, 2003).

Frente a la realidad descrita, resulta necesario analizar el concepto del plazo razonable como elemento teórico vinculante para el propósito del presente trabajo, especialmente, cuando se procura darle una categoría que satisfaga a la ciudadanía, razón por la cual se hace referencia al término humanización. Para ello, utilizaremos algunos conceptos del derecho constitucional y del derecho procesal civil con el fin de evaluar su naturaleza jurídica, de forma que sea posible ampliar sus alcances al final de la presente investigación.

En el ámbito constitucional, por interpretación de los principios del debido proceso y tutela judicial efectiva, se puede apelar a derecho que tienen todas las personas a que se determine su situación jurídica dentro de un plazo razonable (Cáceres Malagón, 2019). Dicha limitación, sin embargo, debe interpretarse en un sentido amplio, porque si advertimos que, dentro de una interpretación sistemática, el plazo razonable corresponde a una vinculación y referencia al debido proceso y a la tutela jurisdiccional, nuestra posición podría encontrar un elemento de referencia vinculante son el ámbito jurisdiccional.

Dada la ambigüedad que puede significar una ausencia normativa, detallaremos los principales elementos referenciales sobre el punto en cuestión, para así proporcionar un elemento vinculante de análisis. El plazo razonable es distinto al plazo legal, debido principalmente a que el primero no se encuentra establecido claramente en norma alguna y porque su duración debería ser menor al plazo establecido por la ley (Corte IDH, 2004). En cambio, el plazo 
legal sí se encuentra regulado por la ley como referencia general y no podría decirse que su inobservancia signifique la vulneración del plazo razonable, pero sí se constituye en un indicio. Con base en estos elementos, Bermúdez-Tapia desarrolla los siguientes aspectos procesales aplicables a la identificación teórica de los tiempos y plazos (2014b).

a. El plazo legal

Es un elemento importante, indistintamente de la condición a la cual se le esté determinando: un proceso constitucional, civil, de familia, penal o administrativo. En este sentido, advertimos que algunos plazos establecidos en la ley procesal debieran ser asimilados por los magistrados para lograr discernir los plazos máximos establecidos por la ley.

b. El plazo máximo

Este elemento está vinculado sobre todo al ámbito de los plazos de caducidad, de lo que se pudo o debió hacer; salvo que la ley admita una prórroga al plazo ya fenecido. Por tratarse de una situación de mucha importancia en el ámbito procesal (sobre todo, en el penal), resulta necesario citar la sentencia de la Corte Interamericana de Derechos Humanos, en el caso Acosta Calderón, en el que esta precisó que la razonabilidad del plazo se debe apreciar en relación con la duración total del proceso, es decir, desde el primer acto procesal hasta que se dicte sentencia definitiva, incluyendo los recursos de instancia que pudieran eventualmente presentarse.

107. [...] cabe destacar que un proceso penal, de conformidad con lo que disponía el Código de Procedimiento Penal de 1983, el cual era aplicable a la presunta víctima, no debía exceder de cien días. Sin embargo, en el caso del señor Acosta Calderón, se extendió por más de cinco años sin que existieran razones que pudieran justificar tal demora. (Corte IDH, 2005)

\section{c. El plazo prudencial}

Este elemento queda determinado, en especial, cuando se regulan condiciones en las cuales se evalúa la restricción de un derecho o la determinación de una condición a favor de una persona en el proceso. En este sentido, se podría señalar como plazo prudencial la ejecución de una serie de condiciones materiales para la validación de una condición de aptitud en un tiempo relativamente corto. 


\section{d. Plazo distinto o irrazonable}

Este plazo se da en función a las condiciones, características, complejidad y circunstancias de los hechos que son objeto de una investigación, generalmente, de naturaleza vinculable a situaciones propias de la interacción de las partes.

e. Plazo no mayor

Es aquel que se establece, principalmente, cuando existe una condición que debe ser confirmada o actuada en el ámbito procesal, por ejemplo, una ampliación de una investigación o la determinación de una carga procesal: el periodo para la atención, tacha o contradicción de un medio probatorio proporcionado por la contraparte, ajeno a las pruebas contenidas en la demanda.

\section{La evaluación de la economía procesal en el ámbito del análisis temporal del trámite de un proceso}

La economía procesal es un principio que hace alusión a un procedimiento por el cual se debe lograr que el proceso judicial se desarrolle con el menor empleo posible de actividades, recursos y tiempos en el órgano jurisdiccional. Dicho esquema referencial, menciona tres condiciones particulares:

a. Un mínimo de intervenciones o actividades por parte de los órganos jurisdiccionales, a efectos de no provocar el alargamiento del proceso en forma innecesaria, con lo cual el principio de imparcialidad judicial pueda verse afectado.

b. El uso de limitados recursos en la ejecución del proceso, recursos que pueden ser diferenciados como:

i. Económicos. En principio, porque la actividad judicial implica en los justiciables la necesidad de contar con una asesoría legal que, según la complejidad del tema en evaluación, puede requerir la intervención de otros actores procesales o la ejecución de actividades particulares para la obtención de los elementos probatorios necesarios para ganar un recurso a su favor.

ii. Humanos. En principio, para no provocar un mayor daño en las partes procesales. 
iii. Temporales. En función a las condiciones de los ciudadanos que son partes procesales, por cuanto la valoración del tiempo dispuesto en el desarrollo del proceso no implica necesariamente una condición negativa en el ámbito jurisdiccional, dado que este resulta ajeno a las condiciones en las cuales se determine la incertidumbre jurídica o el conflicto de intereses.

En este contexto, es el ciudadano quien evalúa las condiciones negativas en las que un proceso puede desarrollarse, en particular, porque el exceso en el tiempo empleado lo perjudica en forma directa. Téngase en cuenta que los recursos empleados en el desarrollo de un proceso en múltiples ocasiones supera el quantum de la materia en evaluación judicial.

Dicha afectación por el uso de un recurso tan complejo como es el tiempo en el trámite jurisdiccional provoca, en múltiples situaciones, una reacción procesal negativa para los intereses del justiciable, la cual está expresamente vinculada al ámbito de figuras procesales como el abandono, la cesión de derechos o la ejecución de procesos de transacción de derechos y obligaciones bajo condiciones peyorativas.

c. La ejecución de una evaluación jurisdiccional eficaz, que implique la decisión del órgano jurisdiccional en una sentencia que defina sobre el fondo de la causa en una única oportunidad. Con esto, la indecisión jurídica del caso y una eventual acción dilatoria no provocarían una mayor afectación al justiciable, toda vez que el conflicto de intereses debería haberse resuelto. Sin embargo, el principio en sí mismo resulta cuestionado por el propio desarrollo del proceso judicial, que está plagado de condiciones internas y externas que limitan su eficacia en cuanto una evaluación temporal.

Entre las condiciones negativas internas de un proceso judicial en la JEP, podemos mencionar la siguiente relación que amplía el plazo temporal en la emisión de una resolución judicial definitiva:

i. La recurrencia en abuso de recursos impugnatorios a los que las partes acceden ante una decisión judicial. A pesar de que existen mecanismos particulares para dotar de eficacia temporal a una decisión 
judicial, los magistrados poco pueden hacer ante la acción litigiosa de una parte procesal. Téngase especial cuidado en la evaluación de los hechos, muchos de los cuales ya han sido ventilados en el ámbito jurisdiccional ordinario y eventualmente no han generado una satisfacción para las víctimas en forma objetiva, especialmente, porque en los lugares donde se presentaba el conflicto armado interno no se brindaban las condiciones apropiadas para desarrollar un proceso judicial en forma objetiva y diligente.

ii. La aplicación de recursos suspensivos de plazos provocados por la intervención de las partes procesales, lo que amplía el plazo de determinación de la controversia jurídica.

Conforme a la proyección institucional de la JEP, es posible prever que en muchos procesos en trámite se observe el tránsito de medidas dilatorias o de impugnación de resoluciones admisorias por parte de la defensa de la parte acusada o denunciada, especialmente en función de la indeterminación de los hechos (Fandiño, 2018).

iii. La mala apreciación de los derechos, obligaciones, condiciones y elementos del proceso por parte del juzgador, ante lo cual las partes procesales plantean las apelaciones respectivas. Téngase en cuenta el contexto social y coyuntural que se produjo en Colombia en pleno conflicto armado interno, situación que justifica nuestra posición.

En el ámbito de las condiciones negativas externas a un proceso judicial, podemos mencionar las siguientes:

i. La sobrecarga judicial de la JEP, situación que incidirá sobre todo en la temporalidad para la emisión de la decisión (Umaña Hernández, 2018).

ii. La actuación diligente y oportuna de las pruebas de oficio, que en múltiples oportunidades limitarán la propia legitimidad del juez, porque se debe tomar en cuenta el contexto alejado respecto el tiempo de los hechos. En forma objetiva, este factor puede provocar un nivel de inseguridad sobre un punto en particular, hecho que puede ser empleado en términos procesales por una contraparte procesal al plantear la prevalencia del principio de inocencia. 
En conjunto, entonces, observamos que el sujeto de derechos que es la parte procesal no recibirá una atención diligente, eficiente, oportuna y proporcional a los hechos de la jurisdicción por parte de la JEP, tanto por cuestiones de fondo como de forma, y ello provoca necesariamente un severo cuestionamiento a los niveles de eficacia del servicio prestado.

\section{Una propuesta de humanización del proceso en la JEP}

Dado que el proceso judicial en su propia esencia no cumple con los objetivos que la sociedad procura alcanzar, la reforma del actual entendimiento de la ejecución de plazos temporales y evaluación del tiempo en el que se desarrolla un proceso - desde la interposición de la demanda hasta la ejecución de la sentencia— requiere de un nuevo ámbito de comprensión, al que se debe agregar un factor humano de sensibilidad ante la evaluación de los hechos por cuanto se atenderán casos propios de un conflicto armado interno (Imbeault, 2018).

En esencia tal comprensión exige que al justiciable se le reasigne su condición de sujeto de derecho, para que así la JEP no considere intrascendente el tiempo en el que se determina una controversia jurídica o conflicto de intereses (Vélez Rodríguez, 2017). Solo de esta manera se puede dotar de un nivel de eficacia al instrumento que procura alcanzar la paz social (Baquer, 1988, p. 215), que es el principal elemento de institucionalidad de la JEP.

Dicha situación implicará que se procure mejorar el servicio de impartición de justicia a través de la ejecución de acciones complementarias, como la mejoría en la sustentación de una decisión judicial que limite las acciones impugnatorias de las partes vencidas, para que de este modo el justiciable no se vea afectado por condiciones ajenas al proceso en la defensa de sus derechos, condiciones e intereses.

Solo cuando un proceso judicial se desarrolla teniendo como premisa básica la atención del justiciable en términos razonables, la propia determinación de derechos y obligaciones que se deriven de la sentencia tendrá una vigencia material, social y humana, con lo cual el sistema de justicia se legitima y se percibe una mejoría en la efectividad del Estado de derecho en el país. 
Como se ha visto, la evaluación de la temporalidad en el desarrollo de un proceso judicial no es solo una cuestión referencial en términos procesales (Rodés Mateu, 2009), sino que implica también una severa crítica a la propia legitimidad de los principios constitucionales aplicables al proceso que, al ser relativizados, provocan la sensación de que jueces y fiscales están evaluando situaciones teóricas, deshumanizando a los sujetos procesales, como el demandante, el demandado, la víctima, el tercero civilmente responsable, etc.

\section{Referencias}

Baquer, M. A. (1998). Las últimas campañas de ultramar. Arbor, 160(630), 215-236. https:// doi.org/10.3989/arbor.1998.i630.1744

Bermúdez-Tapia, M. (2014a). El plazo razonable y su especial importancia en los procesos de familia. Gaceta Constitucional \& Procesal Constitucional, 80, 172-178.

Bermúdez-Tapia, M. (2014b). La humanización del proceso en la búsqueda de una economía procesal eficiente. Actualidad Jurídica, 244.

Cáceres Malagón, J. (2019). La garantía del plazo razonable en la duración de los procesos. Sobre la duración de los procesos judiciales en Colombia conforme al Código General del Proceso. Editorial Académica Española.

Casal, J. (2008). Los derechos humanos y su protección: estudio sobre derechos humanos y derechos fundamentales. Universidad Católica Andrés Bello.

Corte IDH. (2004). Caso Ricardo Canese vs. Paraguay del 31 de agosto de 2004. http://www. corteidh.or.cr/CF/jurisprudencia2/ficha_tecnica.cfm?nId_Ficha $=218$

Corte IDH. (2005). Caso Acosta Calderón vs. Ecuador del 24 de junio de 2005. http://www. corteidh.or.cr/docs/casos/articulos/seriec_129_esp1.pdf

Eser, A., Knust, N., Neumann, U., \& Alvarado, Y. (2018). ¿Es injusta la justicia transicional? Universidad Externado de Colombia.

Fandiño Bohórquez, A. (2018). Participación de las víctimas en la Jurisdicción Especial para la Paz ¿Verdadera participación? Universidad Libre.

Gozaíni, O. (2016). Garantías, principios y reglas del proceso civil. Eudeba.

Imbeault, M. (2018). El destino de los civiles en la nueva guerra justa. Una perspectiva canadiense. Revista Cientifica General José María Córdova, 16(22), 23-36. https://doi. org/10.21830/19006586.322

Lanzarote Martínez, P. (2005). La vulneración del plazo razonable en el proceso penal. Comares.

Padrón, F., \& Correa, M. (2018). ¿El Estado constitucional en jaque? Universidad Externado de Colombia.

Pérez del Blanco, G. (2003). La ejecución forzosa de sentencias en el orden jurisdiccional contencioso-administrativo: doctrina y formularios. Del Blanco 
Rodés Mateu, A. (2009). El derecho a un proceso sin dilaciones indebidas: estudio de su configuración constitucional y de su restablecimiento en el ordenamiento jurídico español. Atelier.

Rosales, E. (2008). Sistema penal y acceso a la justicia. Universidad Central de Venezuela.

Sain, M. F. (2018). ¿Militarización del control del narcotráfico en Argentina? Revista Científica General José María Córdova, 16(24), 61-82. https://doi.org/10.21830/19006586.366

Salazar Murillo, R. (2003). Justicia pronta y mecanismos alternativos: soluciones alternativas, abreviado y plazo razonable en la jurisprudencia penal y constitucional. Investigaciones Jurídicas.

Sierra Zamora, P. A., \& Jiménez Barrera, L. V. (2019). Genealogía de la tortura en Colombia: una mirada desde los derechos humanos. Novum Jus: Revista Especializada en Sociología Jurídica y Política, 13(2), 131-142.

Umaña Hernández, C. (2018). La justicia al encuentro de la paz en contextos de transición: reflexiones actuales para desafíos colombianos. Universidad Externado de Colombia.

Uprimny, R. (2006). Bloque de constitucionalidad, derechos humanos y proceso penal. Escuela Judicial Rodrigo Lara Bonilla.

Vélez Rodríguez, L. (Ed.). (2017). Sociedad y fuerza pública ante los retos de la paz, Justicia Transicional, victimas y consolidación democrática. Grupo Editorial Ibáńez. 